
\title{
3 Research Square \\ Identification of Risk Factors for in-Hospital Death of COVID - 19 Pneumonia
}

\section{Zhigang Wang}

Nanjing University Medical School Affiliated Nanjing Drum Tower Hospital

Zhiqiang Wang ( $\nabla$ medsciwang@yahoo.com)

The central hospital of Tongji medical college https://orcid.org/0000-0001-9344-533X

\section{Research}

Keywords: Characteristics, COVID-19, Risk factors, Therapy, Survivors

Posted Date: May 28th, 2020

DOI: https://doi.org/10.21203/rs.3.rs-30755/v1

License: (c) (i) This work is licensed under a Creative Commons Attribution 4.0 International License. Read Full License 


\section{Abstract}

Objective: To examine the clinical characteristics and identify independent risk factors for in-hospital mortality of 2019 novel coronavirus (COVID-19) pneumonia.

Methods: A total of 156 patients diagnosed with COVID-19 pneumonia at the central Hospital of Wuhan from January 29, 2020, to March 20, 2020 were enrolled in this single-centered retrospective study. Their epidemiological parameters, clinical presentations, underlying diseases, laboratory test results and disease outcomes were collected and analyzed.

Results: The median age of enrolled patients was 66. Underlying diseases were identified in 101 patients, with hypertension being the most common one, followed by cardiovascular disease and diabetes. The most common symptoms identified upon admission were fever, cough, dyspnea and fatigue. Compared to survival cases, patients who dead during hospitalization had higher plasma levels of D-dimer, creatinine, creatine kinase, lactate dehydrogenase, lactate and lower percentage of lymphocytes (LYM $[\%])$, platelet count and albumin levels. Most enrolled patients received anti-biotics and anti-viral treatment. In addition, 60 patients received corticosteroid and 51 received intravenous immunoglobulin infusion. 44 patients received noninvasive ventilation, 19 received invasive ventilation. Respiratory failure was the most frequently observed complication (106 [67.9\%]), followed by sepsis (103 [66.0\%]), acute respiratory distress syndrome (ARDS) $(67$ [42.9\%]) and septic shock (50 [32.1\%]).

Multivariable regression suggested that advanced age (OR [odds ratio] $=1.059,95 \% \mathrm{Cl}$ [confidence interval]: 1.011-1.110, $P=0.016)$ and elevated lactate level upon admission (OR= 2.411, 95\% Cl: $1.177-$ 4.941, $P=0.016$ ) were independent risk factors for in-hospital mortality for COVID-19 infection.

Meanwhile, increased LYM (\%) at admission (OR= 0.798, 95\% Cl: 0.728-0.876, $P<0.001)$ indicated a better prognosis.

Conclusions: In this study, we discovered that age, LYM (\%) and lactate level upon admission were independent factors that could influence in-hospital mortality rate.

\section{Introduction}

Since it first identified, the 2019 novel coronavirus (COVID-19) has relentlessly spread all over the world and infected almost a million people as of April 2, 2020 and taken 45,526 lives [1,2]. The COVID-19 is the seventh member of the notorious coronavirus family [3]. Compared with the $10 \%$ fatal rate in SARS-CoV infection [4] and 37\% in MERS-CoV infection [5], the mortality rate of COVID-19 seems to be lower and has been estimated around 1-5\% [2]. However, the COVID-19 has a higher reproduction number (RO) and much more contagious than its precursors so the overall impact to the global health is enormous. The clinical symptoms of COVID-19 infection are generally mild, and most patients have good prognosis. However, the conditions can deteriorate in about $10-20 \%$ of all patients who often required to be transferred to intensive care unit (ICU) and suffered from a very high mortality rate [6]. 
Due to its latent onset, it is important to early identify patients with increased mortality rate so clinical treatment can be adjusted before disease progression. Even though numerous reports have been published about COVID-19, studies that focusing on identifying such risk factors are still needed. Here in this retrospective analysis, we identified several risk factors that associated with death in COVID-19 patients and assessed the effectiveness of currently treatment strategies.

\section{Methods And Materials}

A total of 156 patients diagnosed with COVID-19 at the Wuhan Central hospital from January 29, 2020, to March 20, 2020 were included in this single-centered retrospective study. The Ethics Committee of Wuhan Central hospital approved this study and waived the individual inform consent due to the retrospective nature of the study.

Epidemiology parameters, clinical presentations, laboratory results and disease outcomes of enrolled patients were collected and reviewed by two independent designated researchers. The blood tested was measured in each patient upon admission or the first available date.

The diagnosis was made following the Chinese COVID-19 management guideline (7th Edition) [7]. More specifically, the diagnosis criteria for the suspected patients required confirmation real-time PCR tests for COVID-19 nucleic acid on patients' throat swabs and/or bronchoalveolar lavage fluid (BALF).

Corticosteroid therapy (methylprednisolone 40-120 mg per day) was given to some patients as indicated. Antibiotics and Oseltamivir were empirically applied to all patients. Oxygen support (nasal cannula, high oxygen flow, noninvasive assisted ventilation, and mechanical ventilation) was applied to patients as needed.

\section{Definitions}

Fever was defined as an axillary temperature above $37.3^{\circ} \mathrm{C}$. Sepsis and septic shock were defined according to the 2016 Third International Consensus Definition for Sepsis and Septic Shock [8]. Acute respiratory distress syndrome (ARDS) was diagnosed according to the Berlin Definition [9]. Acute kidney injury was identified according to the Kidney Disease: Improving Global Outcomes definition (KDIGO) guideline [10]. The acute cardiac injury was diagnosed if serum levels of cardiac enzymes increased above upper limit of the normal value or new abnormalities identified in electrocardiography and echocardiography [6].

Discharge criteria was defined as: body temperature returned to normal and maintained at least three consecutive days; remission of respiratory symptoms; significant improvement on chest computed tomography (CT) scans and negative results on RNA tests on nasopharyngeal swabs obtained at least 24 hours apart.

\section{Statistical analysis}


Data was analyzed with SPSS software for windows (version 25.0 IBM Corp, Armonk, NY). Continuous variables were expressed as median and interquartile (IQR). The student t-test was applied for normally distributed continuous variables and the Mann-Whitney $U$ test for nonnormally distributed variables. Categorical variables were compared with the $\chi^{2}$ test or Fisher exact test.

To identify the risk factors associated with in-hospital death, multivariable logistic regression model (stepwise enter method) was applied. Considering the relatively low number of deaths in the cohort and in order to avoid overfitting in the model, five variables were chosen for multivariable logistic analysis based on previous studies. Advanced age and underlying cardiovascular disease had been reported to associate with adverse clinical outcomes in patients with SARS or MERS infections [11, 12]. Previous COVID-19 studies had shown that the serum levels of D-dimer and lactate were increased in patients with worse prognosis $[13,14]$. In addition, lymphopenia was commonly seen in severe SARS-COV-2 infection $[6,15]$ and it was suggested to be associated with death in a recent COVID-19 study [16]. However, we did not observe significant difference of lymphocyte count in the death cases. Liu and colleagues [17] recently discovered that the percentage of lymphocytes (LYM [\%]) was a potential predictor of COVID-19 severity. Therefore, age, whether complicated with underlying cardiovascular disease or not, LYM (\%), D-dimer and lactate were chosen as the five parameters for the multivariable logistic regression model. Receiveroperating characteristic (ROC) curves were constructed to assess the diagnositic value of above three laboratory test results. The optimal cutoff was first assessed by You-den's index ( $\mathrm{J}=$ Sensitivity + Specificity -1). STATA statistical analysis software was used to assess the difference between the areas under receiver-operating characteristic curve (AUC). $P<0.05$ was considered statistically significant.

\section{Results}

The cohort included in this study consisted of 156 hospitalized patients diagnosed with COVID-19 pneumonia. 56 patients died during hospitalization and 100 were successfully discharged. The median age of all enrolled patients was 66 (IQR, 46.3-73.0; range, 9-99 years), and 76 (48.7\%) were male. Comorbidities were present in 101 (64.7\%) patients, with hypertension, cardiovascular disease and diabetes being the most common ones. The most common symptoms presented upon admission were fever $(79[50.6 \%])$ and cough (71 [45.5\%]), followed by dyspnea (28 [17.9\%]) and fatigue (23 [14.7\%]) (Table 1). 
Table 1

Baseline characteristics of patients infected with COVID-19

$\begin{array}{llll}\text { Total } & \text { Survivor } & \text { Non-survivor } & P \text { value }^{a} \\ (n=156) & (n=100) & (n=56) & \end{array}$

\section{Characteristics}

\begin{tabular}{lllll|} 
Age, years & $66.0(46.3-$ & $58.0(37.0-$ & $72.0(65.3-$ & $<0.001$ \\
\hline Male & $73.0)$ & $69.0)$ & $83.0)$ & 0.115 \\
\hline Underlying disease & $76(48.7)$ & $44(44.0)$ & $32(57.1)$ & \\
Cardiovascular disease & $44(28.2)$ & $17(17.0)$ & $27(48.2)$ & $<0.001$ \\
\hline COPD & $27(17.3)$ & $12(12.0)$ & $15(26.8)$ & 0.019 \\
\hline Chronic renal disease & $15(9.6)$ & $4(4.0)$ & $11(19.6)$ & 0.001 \\
\hline Chronic liver disease & $14(9.0)$ & $2(2.0)$ & $12(21.4)$ & $<0.001$ \\
\hline Cerebrovascular & $22(14.1)$ & $9(9.0)$ & $13(23.2)$ & 0.014 \\
\hline Diabetes & $31(19.9)$ & $11(11.0)$ & $20(35.7)$ & $<0.001$ \\
\hline Hypertension & $65(41.7)$ & $31(31.0)$ & $34(60.7)$ & $<0.001$ \\
\hline Cancer & $14(9.0)$ & $3(3.0)$ & $11(19.6)$ & $<0.001$ \\
\hline Initial symptoms & & & & 0.074 \\
\hline Fever & $79(50.6)$ & $56(56.0)$ & $23(41.4)$ & 0.074 \\
\hline Cough & $71(45.5)$ & $45(45.0)$ & $26(46.4)$ & 0.864 \\
\hline Chest tightness & $28(17.9)$ & $16(16.0)$ & $12(21.4)$ & 0.397 \\
\hline Asthma & $30(19.2)$ & $22(22.0)$ & $8(14.3)$ & 0.241 \\
\hline Headache & $5(3.2)$ & $2(2.0)$ & $3(5.4)$ & 0.351 \\
\hline Myalgia & $2(1.3)$ & $1(1.0)$ & $1(1.8)$ & 1.000 \\
\hline Chill & $4(2.6)$ & $4(4.0)$ & $0(0)$ & 0.297 \\
\hline Nausea or vomiting & $8(5.1)$ & $3(3.0)$ & $5(8.9)$ & 0.136 \\
\hline
\end{tabular}

Notes: Data presented as $\mathrm{n}(\%)$ or median (IQR).

Abbreviations: COVID-19, Coronavirus Disease 2019; IQR, interquartile range; COPD: Chronic obstructive pulmonary disease

a $P$ values indicate differences between survivors and non-survivors. $P<0.05$ was considered statistically significant. 


\begin{tabular}{|c|c|c|c|c|}
\hline & $\begin{array}{l}\text { Total } \\
(n=156)\end{array}$ & $\begin{array}{l}\text { Survivor } \\
(n=100)\end{array}$ & $\begin{array}{l}\text { Non-survivor } \\
(n=56)\end{array}$ & $P$ value ${ }^{a}$ \\
\hline Fatigue & $23(14.7)$ & $8(8.0)$ & $15(26.8)$ & 0.002 \\
\hline Diarrhea & $2(1.3)$ & $1(1.0)$ & $1(1.8)$ & 0.359 \\
\hline Poor appetite & $13(8.3)$ & $4(4.0)$ & $9(16.1)$ & 0.014 \\
\hline $\begin{array}{l}\text { Disturbance of } \\
\text { consciousness }\end{array}$ & $4(2.6)$ & $0(0)$ & $4(7.1)$ & 0.015 \\
\hline \multicolumn{5}{|c|}{ Notes: Data presented as $\mathrm{n}(\%)$ or median (IQR). } \\
\hline \multicolumn{5}{|c|}{$\begin{array}{l}\text { Abbreviations: COVID-19, Coronavirus Disease 2019; IQR, interquartile range; COPD: Chronic } \\
\text { obstructive pulmonary disease }\end{array}$} \\
\hline
\end{tabular}

Compared with successfully discharged patients, the patients who died during hospitalization were older (72.0 years [65.3-83.0] VS 58.0 years [37.0-69.0]), and were more likely complicated with underlying diseases such as hypertension (34 [60.7\%] vs 31 [31.0\%]), diabetes (20 [35.7\%] vs $11[11.0 \%])$, cardiovascular disease (27 [48.2\%] vs 17 [17.0\%]), cerebrovascular disease (13 [23.2\%] vs 9 [9.0\%]), chronic obstructive pulmonary disease (COPD) (15 [26.8\%] vs 12 [12.0\%]), cancer (11 [19.6\%] vs 3 [3.0\%]), chronic renal disease (11 [19.6\%] vs 4 [4.0\%]), and chronic liver disease (12 [21.4\%] vs 2 [2.0\%]). Compared with survivors, non-survivors were more likely to present fatigue (15 [26.8\%] vs 8 [8.0\%]), anorexia (9 [16.1\%] vs $4[4.0 \%]$ ), and neuropsychic symptoms (4 [7.1\%] vs 0) (Table 1).

In terms of laboratory tests, multiple differences between survivors and non-survivors were identified and summarized in Table 2. Specifically, non-survivors had an increased level of white blood cell (WBC) count, neutrophil count, percentage of neutrophils, D-dimer, creatinine, creatine kinase (CK) and lactate dehydrogenase (LDH), as well as higher levels of c-reactive protein (CRP), procalcitonin (PCT) and interleukin-6 (IL-6). Whereas, percentage of lymphocytes, platelet count and albumin levels were significantly lower in non-survivors. In addition, non-survivors had elevated levels of lactate and glucose, accompanied by lower levels of $\mathrm{PaO}_{2} / \mathrm{FiO}_{2}$ (Table 3). 
Table 2

Laboratory findings of patients infected with COVID-19 on admission to hospital

\begin{tabular}{|c|c|c|c|c|}
\hline & $\begin{array}{l}\text { Total } \\
(n=156)\end{array}$ & $\begin{array}{l}\text { Survivor } \\
(n=100)\end{array}$ & $\begin{array}{l}\text { Non-survivor } \\
(n=56)\end{array}$ & $\begin{array}{l}P \\
\text { value }^{\mathrm{a}}\end{array}$ \\
\hline WBC count, $10^{9} / \mathrm{L}$ & $6.2(4.7-8.3)$ & $5.6(4.5-7.2)$ & $7.8(5.5-12.6)$ & $<0.001$ \\
\hline Neutrophil count, $10^{9} / \mathrm{L}$ & $4.0(3.0-6.8)$ & $3.4(2.5-5.0)$ & $6.8(4.5-11.3)$ & $<0.001$ \\
\hline $\begin{array}{l}\text { Lymphocyte count, } \\
10^{9} / \mathrm{L}\end{array}$ & $1.2(0.7-1.7)$ & $1.4(1.0-1.9)$ & $0.7(0.5-1.1)$ & 0.503 \\
\hline $\operatorname{NEU}(\%), \%$ & $71.0(58.9-84.4)$ & $62.9(55.3-72.4)$ & $86.7(76.3-91.0)$ & $<0.001$ \\
\hline LYM (\%), \% & $19.7(10.5-30.6)$ & $27.6(18.4-33.5)$ & $8.7(4.7-14.3)$ & $<0.001$ \\
\hline Hemoglobin, g/L & $\begin{array}{l}123.7(114.2- \\
136.6)\end{array}$ & $\begin{array}{l}125.0(115.5- \\
136.3)\end{array}$ & $\begin{array}{l}122.4(113.9- \\
135.8)\end{array}$ & 0.246 \\
\hline Platelet, $10^{9} / \mathrm{L}$ & $\begin{array}{l}194.0(157.0- \\
249.0)\end{array}$ & $\begin{array}{l}218.5(172.3- \\
259.5)\end{array}$ & $\begin{array}{l}168.0(114.0- \\
200.0)\end{array}$ & $<0.001$ \\
\hline Total bilirubin, mmol/L & $10.9(7.5-17.2)$ & $10.7(7.5-14.6)$ & $13.0(7.5-25.6)$ & 0.057 \\
\hline $\mathrm{LDH}, \mathrm{U} / \mathrm{L}$ & $\begin{array}{l}197.0(159.5- \\
279.0)\end{array}$ & $\begin{array}{l}175.0(149.0- \\
219.0)\end{array}$ & $\begin{array}{l}310.5(201.0- \\
479.3)\end{array}$ & $<0.001$ \\
\hline$A L T, U / L$ & $20.2(13.5-39.5)$ & $19.5(13.0-37.9)$ & $22.1(14.7-41.5)$ & 0.400 \\
\hline AST, U/L & $21.7(16.1-34.2)$ & $18.8(15.1-26.6)$ & $30.0(21.3-55.3)$ & 0.002 \\
\hline Albumin, $\mathrm{g} / \mathrm{L}$ & $37.5(33.8-42.6)$ & $39.9(36.5-43.3)$ & $33.1(29.7-33.6)$ & $<0.001$ \\
\hline Globulin, g/L & $28.7(24.4-32.9)$ & $28.2(24.1-30.9)$ & $31.5(24.8-34.9)$ & 0.014 \\
\hline $\mathrm{BUN}, \mathrm{mmol} / \mathrm{L}$ & $4.7(3.7-6.2)$ & $4.2(3.3-5.3)$ & $6.2(5.0-10.8)$ & $<0.001$ \\
\hline Creatinine, $\mu \mathrm{mol} / \mathrm{L}$ & $66.1(50.3-84.2)$ & $64.8(50.9-75.1)$ & $74.2(47.0-126.9)$ & 0.008 \\
\hline $\mathrm{CK}, \mathrm{U} / \mathrm{L}$ & $68.0(45.0-121.0)$ & $63.0(40.0-96.0)$ & $\begin{array}{l}112.8(62.3- \\
245.0)\end{array}$ & 0.028 \\
\hline CK-MB, U/L & $1.6(0.8-4.6)$ & $0.9(0.7-1.4)$ & $4.3(1.7-13.3)$ & 0.044 \\
\hline
\end{tabular}

Notes: Data presented as $\mathrm{n}(\%)$ or median (IQR).

Abbreviations: COVID-19, Coronavirus Disease 2019; WBC, White blood cell; NEU (\%), Percentage of neutrophils; LYM (\%): Percentage of lymphocytes; LDH, Lactate dehydrogenase; ALT, Alanine aminotransferase; AST, Aspartate aminotransferase; BUN, Blood urea nitrogen; CK, Creatine kinaseMB; CK-MB, Creatine kinase-MB; BNP, Brain natriuretic peptide; CRP, C-reactive protein; IL-6, Interleukin6

a $P$ values indicate differences between survivors and non-survivors. $P<0.05$ was considered statistically significant. 


\begin{tabular}{|c|c|c|c|c|}
\hline & $\begin{array}{l}\text { Total } \\
(n=156)\end{array}$ & $\begin{array}{l}\text { Survivor } \\
(n=100)\end{array}$ & $\begin{array}{l}\text { Non-survivor } \\
(n=56)\end{array}$ & $\begin{array}{l}P \\
\text { value }^{\mathrm{a}}\end{array}$ \\
\hline troponin I, pg/ml & $20.0(4.1-57.5)$ & $10.0(3.0-20.0)$ & $50.0(22.3-115.0)$ & 0.013 \\
\hline BNP, ng/L & 118.5 (32.5-392.7) & $56.8(20.0-132.9)$ & $\begin{array}{l}374.7(135.1- \\
814.5)\end{array}$ & 0.069 \\
\hline D-dimer, mg/L & $1.0(0.4-4.6)$ & $0.7(0.2-1.6)$ & $3.3(1.2-7.8)$ & 0.025 \\
\hline $\mathrm{CRP}, \mathrm{mg} / \mathrm{L}$ & $0.9(0.1-3.6)$ & $0.2(0.1-1.6)$ & $4.1(2.5-7.2)$ & $<0.001$ \\
\hline Procalcitonin, ng/mL & $0.06(0.04-0.14)$ & $0.05(0.04-0.06)$ & $0.37(0.12-0.77)$ & 0.022 \\
\hline $\mathrm{IL}-6, \mathrm{pg} / \mathrm{mL}$ & $7.1(2.4-24.7)$ & $2.9(1.5-7.4)$ & $79.6(9.6-212.5)$ & 0.027 \\
\hline CD19+, count $/ \mu \mathrm{L}$ & $12.6(9.0-18.9)$ & $11.1(8.6-17.0)$ & $16.6(10.1-19.1)$ & 0.292 \\
\hline CD3+, count/ $\mu \mathrm{L}$ & $68.9(57.4-75.3)$ & $70.6(62.0-76.7)$ & $66.8(54.6-71.4)$ & 0.329 \\
\hline $\mathrm{CD} 4+$, count $/ \mu \mathrm{L}$ & $38.8(34.6-46.0)$ & $38.8(31.4-45.2)$ & $39.4(36.2-52.5)$ & 0.183 \\
\hline CD8+, count/ $\mu \mathrm{L}$ & $25.3(19.2-32.3)$ & $26.7(19.6-33.9)$ & $20.5(13.9-30.5)$ & 0.063 \\
\hline CD4/CD8 & $1.6(1.1-2.3)$ & $1.5(1.0-2.1)$ & $1.8(1.2-3.9)$ & 0.071 \\
\hline \multicolumn{5}{|c|}{ Notes: Data presented as $\mathrm{n}(\%)$ or median (IQR). } \\
\hline \multicolumn{5}{|c|}{$\begin{array}{l}\text { Abbreviations: COVID-19, Coronavirus Disease 2019; WBC, White blood cell; NEU (\%), Percentage of } \\
\text { neutrophils; LYM (\%): Percentage of lymphocytes; LDH, Lactate dehydrogenase; ALT, Alanine } \\
\text { aminotransferase; AST, Aspartate aminotransferase; BUN, Blood urea nitrogen; CK, Creatine kinase- } \\
\text { MB; CK-MB, Creatine kinase-MB; BNP, Brain natriuretic peptide; CRP, C-reactive protein; IL-6, Interleukin- } \\
6\end{array}$} \\
\hline \multicolumn{5}{|c|}{$\begin{array}{l}\text { a } P \text { values indicate differences between survivors and non-survivors. } P<0.05 \text { was considered } \\
\text { statistically significant. }\end{array}$} \\
\hline
\end{tabular}


Table 3

Blood gas analysis of patients infected with COVID-19

\begin{tabular}{|c|c|c|c|c|}
\hline & $\begin{array}{l}\text { Total } \\
(n=156)\end{array}$ & $\begin{array}{l}\text { Survivor } \\
(n=100)\end{array}$ & $\begin{array}{l}\text { Non-survivor } \\
(n=56)\end{array}$ & $P$ value \\
\hline $\mathrm{Ph}$ & $7.44(7.39-7.47)$ & $7.43(7.40-7.46)$ & 7.45 (7.39-7.48) & 0.970 \\
\hline $\mathrm{PaO}_{2}, \mathrm{~mm} \mathrm{Hg}$ & $91.0(64.3-119.0)$ & $95.0(79.0-129.0)$ & $72.0(50.0-116.0)$ & 0.049 \\
\hline $\mathrm{PaO}_{2} / \mathrm{FiO}_{2}, \mathrm{~mm} \mathrm{Hg}$ & $195.0(90.0-262.5)$ & $225.0(152.5-287.5)$ & 117.5 (78.3-192.9) & $<0.001$ \\
\hline $\mathrm{PaCO}_{2}, \mathrm{~mm} \mathrm{Hg}$ & $38.0(34.0-42.0)$ & $40.0(35.0-45.0)$ & $36.0(33.0-40.0)$ & 0.113 \\
\hline $\mathrm{BE}, \mathrm{mmol} / \mathrm{L}$ & $1.9(-0.7-4.1)$ & $2.1(-0.1-3.9)$ & $1.2(-1.8-4.6)$ & 0.300 \\
\hline $\mathrm{K}^{+}, \mathrm{mmol} / \mathrm{L}$ & $3.8(3.4-4.1)$ & $3.8(3.5-4.2)$ & $3.8(3.3-4.1)$ & 0.768 \\
\hline $\mathrm{Na}^{+}, \mathrm{mmol} / \mathrm{L}$ & $140.0(136.0-143.8)$ & $141.0(138.0-144.0)$ & $137.0(133.0-142.0)$ & 0.641 \\
\hline $\mathrm{Ca}^{2+}, \mathrm{mmol} / \mathrm{L}$ & $0.9(0.7-1.0)$ & $0.9(0.7-1.1)$ & $0.9(0.7-1.0)$ & 0.482 \\
\hline Lactate, $\mathrm{mmol} / \mathrm{L}$ & $1.7(1.2-2.3)$ & $1.5(1.1-2.1)$ & $2.0(1.5-2.9)$ & 0.005 \\
\hline Hematocrit, \% & $37.0(32.0-41.0)$ & $38.0(32.5-42.0)$ & $36.0(30.0-40.0)$ & 0.627 \\
\hline Glucose, mmol/L & $6.7(5.4-8.7)$ & $5.9(4.9-7.9)$ & $7.4(6.2-11.1)$ & 0.034 \\
\hline \multicolumn{5}{|c|}{ Notes: Data presented as median (IQR). } \\
\hline \multicolumn{5}{|c|}{$\begin{array}{l}\text { Abbreviations: COVID-19, Coronavirus Disease 2019; } \mathrm{PaO}_{2} \text {, Partial pressure of oxygen; } \mathrm{PaO}_{2}, \text { Partial } \\
\text { pressure of carbon dioxide; } \mathrm{BE} \text {, Base excess }\end{array}$} \\
\hline \multicolumn{5}{|c|}{$\begin{array}{l}\text { a } P \text { values indicate differences between survivors and non-survivors. } P<0.05 \text { was considered } \\
\text { statistically significant. }\end{array}$} \\
\hline
\end{tabular}

150 (96.2\%) patients received antibiotics and 139 (89.1\%) received antiviral treatment. Unsurprisingly, systematic corticosteroid was more commonly applied in non-survivors. 56 patients $(35.9 \%)$ received high-flow nasal cannula oxygen therapy, 44 (28.2\%) received non-invasive mechanical ventilation and 19 patients $(12.2 \%)$ required invasive mechanical ventilation support. 6 patients $(3.8 \%)$ received renal replacement therapy (RRT) and no patients were treated with extracorporeal membrane oxygenation therapy. Oxygen support (including high oxygen flow, noninvasive assisted ventilation, and mechanical ventilation) and renal replacement therapy were more commonly applied in non-survivors (Table 4). 
Table 4

Treatments of patients infected with COVID-19

\begin{tabular}{|lllll|}
\hline & $\begin{array}{l}\text { Total } \\
(\mathbf{n = 1 5 6 )}\end{array}$ & $\begin{array}{l}\text { Survivor } \\
(\mathbf{n = 1 0 0})\end{array}$ & $\begin{array}{l}\text { Non-survivor } \\
(\mathbf{n = 5 6})\end{array}$ & Pvalue $^{\mathbf{a}}$ \\
\hline Antibiotics & $150(96.2)$ & $96(96.0)$ & $54(96.4)$ & 1.000 \\
\hline Antiviral treatment & $139(89.1)$ & $89(89.0)$ & $50(89.3)$ & 0.956 \\
\hline Corticosteroids & $60(38.5)$ & $22(22.0)$ & $38(67.9)$ & $<0.001$ \\
\hline Intravenous immunoglobulin & $51(32.7)$ & $18(18.0)$ & $33(58.9)$ & $<0.001$ \\
\hline High-flow nasal cannula oxygen therapy & $56(35.9)$ & $26(26.0)$ & $30(53.6)$ & 0.001 \\
\hline Non-invasive mechanical ventilation & $44(28.2)$ & $13(13.0)$ & $31(55.4)$ & $<0.001$ \\
\hline Invasive mechanical ventilation & $19(12.2)$ & $1(1.0)$ & $18(32.1)$ & $<0.001$ \\
\hline RRT & $6(3.8)$ & $1(1.0)$ & $5(8.9)$ & 0.023 \\
\hline Notes: Data presented as $n$ (\%). & & & \\
\hline Abbreviations: COVID-19, Coronavirus Disease 2019; RRT, Renal replacement therapy & \\
\hline $\begin{array}{l}\text { a } P \text { values indicate differences between survivors and non-survivors. } P<0.05 \text { was considered } \\
\text { statistically significant. }\end{array}$ & \\
\hline
\end{tabular}

The clinical outcomes of the enrolled 156 patients were summarized in Table 5. Unsurprisingly, nonsurvivor patients were more likely to develop complications compared with survivors. Respiratory failure was the most frequently developed complication (106 [67.9\%]), followed by sepsis (103 [66.0\%]), ARDS (67 [42.9\%]), septic shock (50 [32.1\%]), arrhythmia (42 [26.9\%]), acute cardiac injury (26 [16.7\%]), cardiac failure (24 [15.4\%]), and acute kidney injury (18 [11.5\%]). The median time from disease onset to admission was 10.0 days (IQR 4.3-16.0). And the median time from disease onset to discharge was 36.0 days (IQR 27.3-48.0), whereas the median time to death was 17.0 days (IQR 10.0-26.5). After comparing the time from disease onset to hospital admission and total hospital stay between non-survivors with survivors [(median time, 6.0 days [1.0-10.0] vs 14.5 days [7.0-20.0]) and (median time, 9.0 days [3.3$16.0]$ vs 22.0 days [16.0-29.0]) respectively], it seemed like the disease progressed more rapidly in nonsurvivors. 
Table 5

Outcomes of patients infected with COVID-19

\begin{tabular}{|c|c|c|c|c|}
\hline & $\begin{array}{l}\text { Total } \\
(n=156)\end{array}$ & $\begin{array}{l}\text { Survivor } \\
(n=100)\end{array}$ & $\begin{array}{l}\text { Non-survivor } \\
(n=56)\end{array}$ & $\begin{array}{l}P \\
\text { value }^{\mathrm{a}}\end{array}$ \\
\hline Arrhythmia & $42(26.9)$ & $13(13.0)$ & $29(51.8)$ & $<0.001$ \\
\hline Sepsis & $103(66.0)$ & $49(49.0)$ & $54(96.4)$ & $<0.001$ \\
\hline ARDS & $67(42.9)$ & $17(17.0)$ & $50(89.3)$ & $<0.001$ \\
\hline Respiratory failure & $106(67.9)$ & $50(50.0)$ & $56(100)$ & $<0.001$ \\
\hline Cardiac failure & $24(15.4)$ & $11(11.0)$ & $13(35.9)$ & 0.043 \\
\hline Septic shock & $50(32.1)$ & $9(9.0)$ & $41(73.2)$ & $<0.001$ \\
\hline Acute kidney injury & $18(11.5)$ & $8(8.0)$ & $15(26.8)$ & 0.002 \\
\hline Acute cardiac injury & $26(16.7)$ & $6(6.0)$ & $20(35.7)$ & $<0.001$ \\
\hline Onset to admission, days & $\begin{array}{l}10.0(4.3- \\
16.0)\end{array}$ & $14.5(7.0-20.0)$ & $6.0(1.0-10.0)$ & $<0.001$ \\
\hline Hospitalization, days & $\begin{array}{l}18.0(11.0- \\
27.8)\end{array}$ & $\begin{array}{l}22.0(16.0- \\
29.0)\end{array}$ & $9.0(3.3-16.0)$ & $<0.001$ \\
\hline $\begin{array}{l}\text { Onset to discharge or death, } \\
\text { days }\end{array}$ & $\begin{array}{l}30.0(21.0- \\
42.8)\end{array}$ & $\begin{array}{l}36.0(27.3- \\
48.0)\end{array}$ & $\begin{array}{l}17.0(10.0- \\
26.5)\end{array}$ & $<0.001$ \\
\hline \multicolumn{5}{|c|}{ Notes: Data presented as $\mathrm{n}(\%)$ or median (IQR). } \\
\hline \multicolumn{5}{|c|}{ Abbreviations: COVID-19, Coronavirus Disease 2019; ARDS, Acute respiratory distress syndrome } \\
\hline
\end{tabular}

Next, we analyzed variables introduced above in the methods section by multivariable logistic regression assay and discovered that age (OR [odds ratio] $=1.059,95 \% \mathrm{Cl}$ [confidence interval]: 1.011-1.110, $P=$ 0.016), LYM (\%) at admission (OR $=0.798,95 \% \mathrm{Cl}: 0.728-0.876, P<0.001)$, and lactate at admission (OR $=2.411,95 \% \mathrm{Cl}: 1.177-4.941, \mathrm{P}=0.016)$ were independent risk factors for in-hospital death of COVID-19 pneumonia (Table 6). 
Table 6

\begin{tabular}{|c|c|c|c|}
\hline & OR & $95 \% \mathrm{Cl}$ & $P$ value \\
\hline Age & 1.059 & $1.011-1.110$ & 0.016 \\
\hline Cardiovascular disease & 1.835 & $0.554-6.073$ & 0.320 \\
\hline LYM (\%) & 0.798 & $0.728-0.876$ & $<0.001$ \\
\hline D-dimer & 0.974 & $0.935-1.015$ & 0.209 \\
\hline Lactate & 2.411 & $1.177-4.941$ & 0.016 \\
\hline \multicolumn{4}{|c|}{ Abbreviations: COVID-19, Coronavirus Disease 2019; OR, Odds ratio } \\
\hline \multicolumn{4}{|l|}{$\mathrm{Cl}$, Confidence interval } \\
\hline
\end{tabular}

In addition, we conducted the ROC curve assay and calculated the AUC among these three indicators. We discovered that the AUC of LYM (\%) was $0.903(95 \% \mathrm{Cl}, 0.856-0.949), 0.792$ (95\% Cl, 0.720-0.863) for Ddimer and of 0.651 (95\% Cl, 0.555-0.748) for lactate. (Fig. 1) Comparing to the other indicators, the AUC of LYM (\%) was higher in predicting in-hospital death of COVID-19 pneumonia (LYM [\%] VS D-dimer, $P=$ 0.003; LYM [\%] VS lactate, $P<0.001$; respectively). Furthermore, we discovered that the cutoff value of LYM (\%) for predicting in-hospital death was $14.7 \%$.

\section{Discussion}

In this study we reported a cohort of 156 patients with laboratory-confirmed COVID-19 pneumonia. After carefully summarized and compared patients' clinical characteristics, we identified several risk factors for in-hospital death. In specific, our data suggested that advanced age, decreased LYM (\%) and increased lactate at admission were associated with higher odds of in-hospital death. Additionally, we also found that non-survivors were older, more likely to complicate with underlying comorbidities and with a more rapidly progressed disease course.

Wuhan Central hospital is the largest tertiary hospital around Huanan Seafood Wholesale Market area, where speculated to be ground zero for this pandemic [18-20]. As the matter of fact that most of the enrolled patents lived close to this market, our data might include a large portion of patients with so called " primary infection". To the best of our knowledge, this is the largest single-centered retrospective cohort study about patients with COVID-19 who had definite outcomes and complete disease courses. Comparing with other reports $[6,15,16]$, patients included in our cohort were older and complicated with more comorbidities. It seemed like that the patients in our study were much severer when they were diagnosed and had a longer hospital stay. 
Our data suggested symptoms that were more common in critically ill patient were fatigue, anorexia and neuropsychic symptoms. The onset and persistent of these symptoms might suggest an unfavorable prognosis. Time from disease onset to admission and death was much shorter for non-survivors, which might imply a more rapid disease progression.

After carefully reviewed the medical records of all enrolled patients, we found that $26.9 \%$ of patients with COVID-19 pneumonia presented with arrhythmia and $16.7 \%$ complicated with acute cardiac injuries. Further analysis indicated that the incidence of myocardial injury was much higher in non-survivors. In Li's report [21], they found at least 8\% of patients with COVID-19 suffered acute cardiac injury and this ratio was 12\% in Wang's research [15]. Gao et al. reported that NT-proBNP might be an independent risk factor for in-hospital death in patients with severe COVID-19 [22]. The pathogenesis of COVID-19 infection-related acute myocardial injury is still under-studied. But according to the clinical presentation and available laboratory results, we speculated that the direct assault from the virus, hypoxemia induced by pneumonia and over-reacting immune response all play important roles in the pathogenesis.

Consistently, our study confirmed that advanced age was associated with death in patients with COVID19, as reported by Zhou and colleagues [16]. Previously, advanced age has been identified as an important predictor of mortality in SARS and MERS infection [23,24]. Though has not been verified in mechanism studies, several reasons may contribute to this age-related vulnerability: firstly, aged patients are usually with decreased cardiopulmonary compliance and reserve thus more difficult in coping with the disequilibrium of cardiopulmonary system induced by COVID-19 infection; secondly, the immune system in aged patients are usually incompetent and has an increased risks of both under- and over-react with the virus infection [25, 26]; thirdly, aged patients have an increased risk of having comorbidities which has been proved in several studies associate with worse prognosis; finally, the diagnosis and treatments in patients with advanced ages are more likely to be delayed due to atypical symptoms. Thus, attention should be paid to COVID-19 patients with advanced ages, especially to whom having multiple comorbidities.

The multivariable logistic regression assay suggested that the decreased LYM (\%) was an independent risk factor for in-hospital death and further analysis concluded that LYM (\%) was a stronger indicator in predicting in-hospital death of COVID-19 pneumonia indicated by the ROC assay. Previous studies showed that lymphopenia was a risk factor for increased mortality rate for SARS and COVID-19 [16, 27]. While in our study, there was no statistical difference observed in terms of lymphopenia between survivors and non-survivors. Liu and colleagues [17] demonstrated the percentage of lymphocytes (LYM [\%]) was a potential predictor of COVID-19 severity. Considering the fact that the WBC counts was significantly higher in the non-survivors in our cohort and might biased the result, we substituted the absolute lymphocyte count with the LYM [\%] in the regression analysis model and repeated the assay. The decreased LYM (\%) might be explained by the fact that coronavirus was able to destroy lymphocytes during an acute process. The decreased LYM\% may reflect an under-activation and/or over exhausting of the immune system that consequently unable to contain COVID-19 infection. 
Serum lactate was identified as another risk factor associated with in-hospital death in our study. Lactate has been used as a prognostic marker in predicting the severity and outcome of sepsis and septic shock [28]. Shankar-Hari et al. suggested in their study that the adjusted odds ratio for hospital mortality increased linearly with increasing lactate levels with lactate level $>2 \mathrm{mmol} / \mathrm{L}$ being the cutoff value for the diagnosis of septic shock [29]. This finding had been further confirmed by some recent studies [14, $30,31]$. In sepsis, patients usually experience hyperlactatemia as a consequence of tissue hypoperfusion, as well as a diminished lactate clearance rate due to dysfunction of the liver and kidney [32]. In consistent with our study, Zhou and colleagues [16] identified that sepsis and septic shock were a major complication for COVID-19 patients. Measurement of serum lactate seems to be a simple yet effective strategy to identify patients with increased risks.

A previous study suggested that about $90 \%$ of patients with severe pneumonia had increased coagulation activity, marked by the increased D-dimer concentrations [33]. High levels of D-dimer was proved to be associated with increased mortality rate in patients with sepsis identified in the emergency room [13]. Previous research also demonstrated that D-dimer greater than $1 \mathrm{ug} / \mathrm{ml}$ was associated with fatal outcome of COVID-19 [16]. While in our study, D-dimer was not identified as an independent risk factor for in-hospital death. This discrepancy may be due to the difference of patients selection and future research includes a larger population is needed to confirm the conclusions.

\section{Limitations}

This study had several limitations. Firstly, this study was a retrospective study conducted in a single center, with a cohort that might not necessarily representable for the general population. Secondly, by excluding patients still in hospital receiving treatment as of March 20,2020, the mortality rate in our study might be biased. Finally, the lack of more effective antiviral drugs and life support methods like extracorporeal membrane oxygenation in our hospital might contribute to the poor clinical outcomes in some severe patients.

\section{Conclusions}

Our study indicated that the non-survivors were older and with a disease course that progressed more rapidly compared to survivors. Advanced age, decreased LYM (\%), and increased lactate level upon hospital admission were independent risk factors for in-hospital death of patients with COVID-19.

\section{Abbreviations}

COVID-19, 2019-novel coronavirus; OR, Odds ratio; Cl, Confidence interval; LYM (\%), Percentage of lymphocytes; ARDS, Acute respiratory distress syndrome; ROC, Receiver-operating characteristic; ICU, Intensive care unit; BALF, Bronchoalveolar lavage fluid; ARDS, Acute respiratory distress syndrome; KDIGO, Kidney Disease: Improving Global Outcomes; CT, Computed tomography; AUC, Areas under receiveroperating characteristic curve. MERS, Middle east respiratory syndrome; COPD, Chronic obstructive 
pulmonary disease; WBC, White blood cell; CK, Creatine kinase; LDH, Lactate dehydrogenase; CRP, Creactive protein; PCT, Procalcitonin; IL-6, Interleukin-6; IQR, Interquartile range; NEU (\%), Percentage of neutrophils; ALT, Alanine aminotransferase; AST, Aspartate aminotransferase; BUN, Blood urea nitrogen; CK-MB, Creatine kinase-MB; BNP, Brain natriuretic peptide; $\mathrm{PaO2}$, Partial pressure of oxygen; $\mathrm{PaCO} 2$, Partial pressure of carbon dioxide; BE, Base excess; RRT, Renal replacement therapy

\section{Declarations}

\section{Acknowledgements}

Not applicable.

\section{Authors' contributions}

All authors were major contributors in writing the manuscript and approved the final manuscript.

\section{Funding}

The authors received no internal or external funding from their institution or department.

\section{Availability of data and materials}

All data generated or analyzed during this study are included in this published article.

\section{Ethics approval and consent to participate}

Not applicable.

\section{Consent for publication}

Not applicable.

\section{Competing interests}

The authors have declared they have no interest.

\section{References}


1. Wang C, Horby PW, Hayden FG, Gao GF. A novel coronavirus outbreak of global health concern. Lancet. 2020;395(10223):470-3. Epub 2020/01/28. doi: 10.1016/S0140-6736(20)30185-9. PubMed PMID: 31986257.

2. WHO. Coronavirus disease (COVID-2019) situation reports. 2020. Available from: https://www.who.int/docs/default-source/coronaviruse/situation-reports/20200402-sitrep-73-covid19.pdf?sfvrsn=5ae25bc7_2. Accessed 2 April 2020.

3. Chan JF, Yuan S, Kok KH, To KK, Chu H, Yang J, et al. A familial cluster of pneumonia associated with the 2019 novel coronavirus indicating person-to-person transmission: a study of a family cluster. Lancet. 2020;395(10223):514-23. Epub 2020/01/28. doi: 10.1016/S0140-6736(20)30154-9. PubMed PMID: 31986261.

4. Jiang Y, Xu J, Zhou C, Wu Z, Zhong S, Liu J, et al. Characterization of cytokine/chemokine profiles of severe acute respiratory syndrome. Am J Respir Crit Care Med. 2005;171(8):850-7. Epub 2005/01/20. doi: 10.1164/rccm.200407-8570C. PubMed PMID: 15657466.

5. Ko JH, Park GE, Lee JY, Lee JY, Cho SY, Ha YE, et al. Predictive factors for pneumonia development and progression to respiratory failure in MERS-CoV infected patients. J Infect. 2016;73(5):468-75. Epub 2016/08/16. doi: 10.1016/j.jinf.2016.08.005. PubMed PMID: 27519621.

6. Huang C, Wang Y, Li X, Ren L, Zhao J, Hu Y, et al. Clinical features of patients infected with 2019 novel coronavirus in Wuhan, China. Lancet. 2020;395(10223):497-506. Epub 2020/01/28. doi: 10.1016/S0140-6736(20)30183-5. PubMed PMID: 31986264.

7. China tNHCo. Interpretation of pneumonia diagnosis and treatment scheme for novel coronavirus infection (trial version 5). Available from: http://www.nhc.gov.cn/yzygj/s7652m/202003/a31191442e29474b98bfed5579d5af95.shtml. Accessed 4 Mar 2020.

8. Singer M, Deutschman CS, Seymour CW, Shankar-Hari M, Annane D, Bauer M, et al. The Third International Consensus Definitions for Sepsis and Septic Shock (Sepsis-3). JAMA. 2016;315(8):80110. Epub 2016/02/24. doi: 10.1001/jama.2016.0287. PubMed PMID: 26903338; PubMed Central PMCID: PMCPMC4968574.

9. Force ADT, Ranieri VM, Rubenfeld GD, Thompson BT, Ferguson ND, Caldwell E, et al. Acute respiratory distress syndrome: the Berlin Definition. JAMA. 2012;307(23):2526-33. Epub 2012/07/17. doi: 10.1001/jama.2012.5669. PubMed PMID: 22797452.

10. Kidney Disease: Improving Global Outcomes(KDIGO) Acute Kidney Injury Work Group. KDIGO Clinical Practice Guideline for Acute Kidney Injury. Kidney inter. 2012;2 (Suppl):1-138.

11. Chan JW, Ng CK, Chan YH, Mok TY, Lee S, Chu SY, et al. Short term outcome and risk factors for adverse clinical outcomes in adults with severe acute respiratory syndrome (SARS). Thorax. 2003;58(8):686-9. Epub 2003/07/30. doi: 10.1136/thorax.58.8.686. PubMed PMID: 12885985; PubMed Central PMCID: PMCPMC1746764.

12. Arabi YM, Balkhy HH, Hayden FG, Bouchama A, Luke T, Baillie JK, et al. Middle East Respiratory Syndrome. N Engl J Med. 2017;376(6):584-94. Epub 2017/02/09. doi: 10.1056/NEJMsr1408795. 
PubMed PMID: 28177862; PubMed Central PMCID: PMCPMC5362064.

13. Rodelo JR, De la Rosa G, Valencia ML, Ospina S, Arango CM, Gomez Cl, et al. D-dimer is a significant prognostic factor in patients with suspected infection and sepsis. Am J Emerg Med.

2012;30(9):1991-9. Epub 2012/07/17. doi: 10.1016/j.ajem.2012.04.033. PubMed PMID: 22795996.

14. Goyal N, Taylor AR, Rivers EP. Relationship between Central and Peripheral Venous Oxygen Saturation and Lactate Levels: A Prospective Study. J Emerg Med. 2016;50(6):809-17. Epub 2016/05/24. doi: 10.1016/j.jemermed.2016.03.021. PubMed PMID: 27210904.

15. Wang D, Hu B, Hu C, Zhu F, Liu X, Zhang J, et al. Clinical Characteristics of 138 Hospitalized Patients With 2019 Novel Coronavirus-Infected Pneumonia in Wuhan, China. JAMA. 2020. Epub 2020/02/08. doi: 10.1001/jama.2020.1585. PubMed PMID: 32031570; PubMed Central PMCID: PMCPMC7042881.

16. Zhou F, Yu T, Du R, Fan G, Liu Y, Liu Z, et al. Clinical course and risk factors for mortality of adult inpatients with COVID-19 in Wuhan, China: a retrospective cohort study. Lancet.

2020;395(10229):1054-62. Epub 2020/03/15. doi: 10.1016/S0140-6736(20)30566-3. PubMed PMID: 32171076.

17. Liu Y, Yang Y, Zhang C, Huang F, Wang F, Yuan J, et al. Clinical and biochemical indexes from 2019nCoV infected patients linked to viral loads and lung injury. Sci China Life Sci. 2020. Epub 2020/02/13. doi: 10.1007/s11427-020-1643-8. PubMed PMID: 32048163.

18. Wu F, Zhao S, Yu B, Chen YM, Wang W, Song ZG, et al. A new coronavirus associated with human respiratory disease in China. Nature. 2020;579(7798):265-9. Epub 2020/02/06. doi: 10.1038/s41586020-2008-3. PubMed PMID: 32015508; PubMed Central PMCID: PMCPMC7094943.

19. Paules $\mathrm{Cl}$, Marston HD, Fauci AS. Coronavirus Infections-More Than Just the Common Cold. JAMA. 2020. Epub 2020/01/24. doi: 10.1001/jama.2020.0757. PubMed PMID: 31971553.

20. Chen N, Zhou M, Dong X, Qu J, Gong F, Han Y, et al. Epidemiological and clinical characteristics of 99 cases of 2019 novel coronavirus pneumonia in Wuhan, China: a descriptive study. Lancet. 2020;395(10223):507-13. Epub 2020/02/03. doi: 10.1016/S0140-6736(20)30211-7. PubMed PMID: 32007143.

21. Li B, Yang J, Zhao F, Zhi L, Wang X, Liu L, et al. Prevalence and impact of cardiovascular metabolic diseases on COVID-19 in China. Clin Res Cardiol. 2020. Epub 2020/03/13. doi: 10.1007/s00392-02001626-9. PubMed PMID: 32161990.

22. Gao L, Jiang D, Wen XS, Cheng XC, Sun M, He B, et al. Prognostic value of NT-proBNP in patients with severe COVID-19. Respir Res. 2020;21(1):83. Epub 2020/04/16. doi: 10.1186/s12931-020-01352-w. PubMed PMID: 32293449; PubMed Central PMCID: PMCPMC7156898.

23. Liu M, Liang WN, Chen Q, Xie XQ, Wu J, He X, et al. Risk factors for SARS-related deaths in 2003, Beijing. Biomed Environ Sci. 2006;19(5):336-9. Epub 2006/12/28. PubMed PMID: 17190184.

24. Ahmadzadeh J, Mobaraki K, Mousavi SJ, Aghazadeh-Attari J, Mirza-Aghazadeh-Attari M, Mohebbi I. The risk factors associated with MERS-CoV patient fatality: A global survey. Diagn Microbiol Infect 
Dis. 2020;96(3):114876. Epub 2020/01/22. doi: 10.1016/j.diagmicrobio.2019.114876. PubMed PMID: 31959375.

25. Mouton CP, Bazaldua OV, Pierce B, Espino DV. Common infections in older adults. Am Fam Physician. 2001;63(2):257-68. Epub 2001/02/24. PubMed PMID: 11201692.

26. Yoshikawa TT, Norman DC. Geriatric Infectious Diseases: Current Concepts on Diagnosis and Management. J Am Geriatr Soc. 2017;65(3):631-41. Epub 2017/02/01. doi: 10.1111/jgs.14731. PubMed PMID: 28140454.

27. Hu X, Deng Y, Wang J, Li H, Li M, Lu Z. Short term outcome and risk factors for mortality in adults with critical severe acute respiratory syndrome (SARS). J Huazhong Univ Sci Technolog Med Sci. 2004;24(5):514-7. Epub 2005/01/12. doi: 10.1007/bf02831124. PubMed PMID: 15641708; PubMed Central PMCID: PMCPMC7088722.

28. Oh DH, Kim MH, Jeong WY, Kim YC, Kim EJ, Song JE, et al. Risk factors for mortality in patients with low lactate level and septic shock. J Microbiol Immunol Infect. 2019;52(3):418-25. Epub 2017/09/20. doi: 10.1016/j.jmii.2017.08.009. PubMed PMID: 28923305.

29. Shankar-Hari M, Phillips GS, Levy ML, Seymour CW, Liu VX, Deutschman CS, et al. Developing a New Definition and Assessing New Clinical Criteria for Septic Shock: For the Third International Consensus Definitions for Sepsis and Septic Shock (Sepsis-3). JAMA. 2016;315(8):775-87. Epub 2016/02/24. doi: 10.1001/jama.2016.0289. PubMed PMID: 26903336; PubMed Central PMCID: PMCPMC4910392.

30. Mikkelsen ME, Miltiades AN, Gaieski DF, Goyal M, Fuchs BD, Shah CV, et al. Serum lactate is associated with mortality in severe sepsis independent of organ failure and shock*. Critical Care Medicine. 2009;37(5):1670-7. doi: 10.1097/CCM.0b013e31819fcf68.

31. Chen H, Zhao C, Wei Y, Jin J. Early lactate measurement is associated with better outcomes in septic patients with an elevated serum lactate level. Crit Care. 2019;23(1):351. Epub 2019/11/13. doi: 10.1186/s13054-019-2625-0. PubMed PMID: 31711512; PubMed Central PMCID: PMCPMC6849274.

32. Suetrong B, Walley KR. Lactic Acidosis in Sepsis: It's Not All Anaerobic: Implications for Diagnosis and Management. Chest. 2016;149(1):252-61. Epub 2015/09/18. doi: 10.1378/chest.15-1703. PubMed PMID: 26378980.

33. Milbrandt EB, Reade MC, Lee M, Shook SL, Angus DC, Kong L, et al. Prevalence and significance of coagulation abnormalities in community-acquired pneumonia. Mol Med. 2009;15(11-12):438-45. Epub 2009/09/16. doi: 10.2119/molmed.2009.00091. PubMed PMID: 19753144; PubMed Central PMCID: PMCPMC2743205.

\section{Figures}




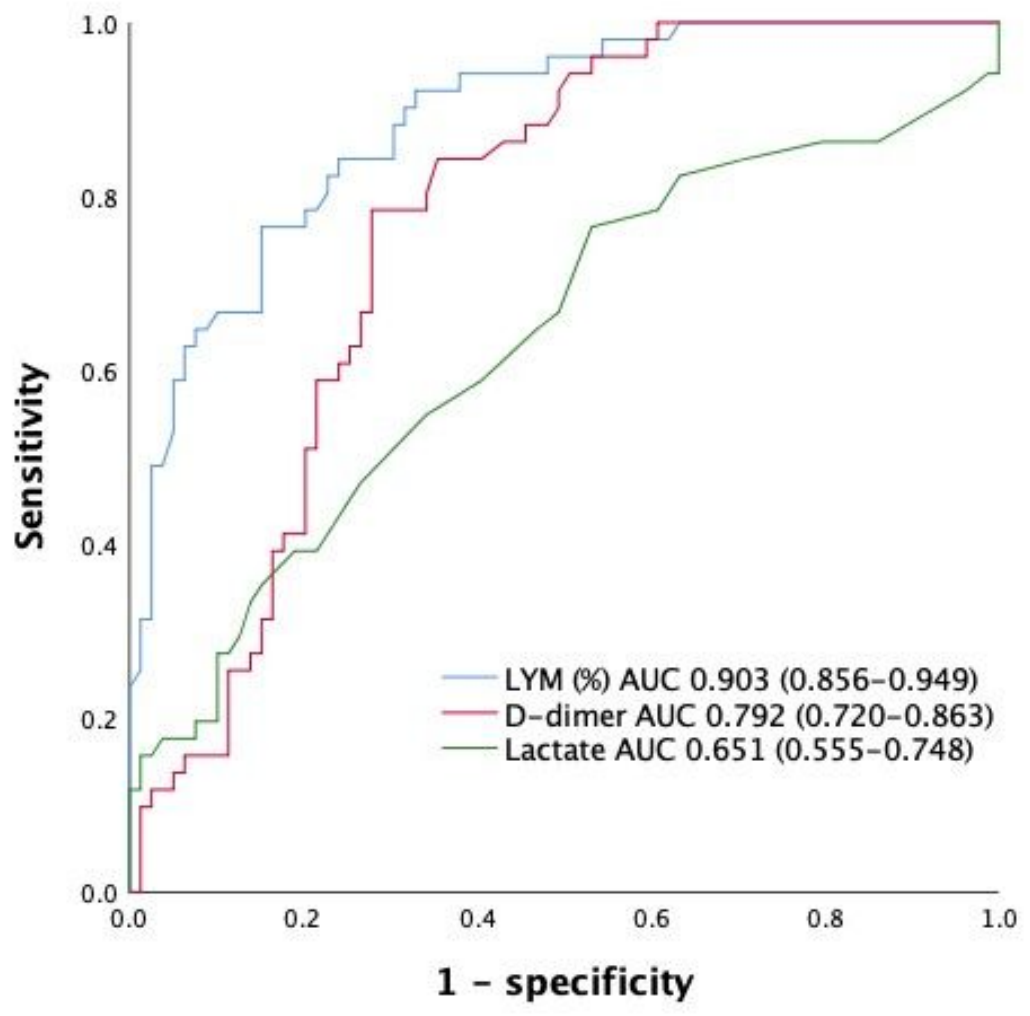

Figure 1

Receiver-operating characteristic of LYM (\%), D-dimer and lactate upon hospital admission (AUC= areas under receiver-operating characteristic curve; $L Y M[\%]=$ percentage of lymphocytes.) 